\title{
HOW CAN PRIVATE HOSPITALS BE USED AS A SOLUTION TO PROVIDE OUTFLOW SURGE CAPACITY TO PUBLIC HOSPITALS DURING MASS CASUALTY INCIDENTS
}

\author{
Arlene Minnock ${ }^{1,2} \odot$, Hany Ebeid ${ }^{3}$ \\ ${ }^{1}$ Vrije University, Ixelles, Belgium \\ ${ }^{2}$ Beacon Hospital, Sandyford, Dublin, Ireland \\ ${ }^{3}$ Johns Hopkins Aramco Healthcare, Almond Ln, Najmah, Ras Tanura, Saudi Arabia
}

\begin{abstract}
INTRODUCTION: Private hospitals are not utilised as a part of a solution in Ireland in the event of Mass Casualty Incidents $(\mathrm{MCl})$ in Ireland. While disaster planning is evident in each hospital and there is also a national plan in place, no plan details the difficulties public hospitals are facing on a daily basis with overcrowding in both Emergency Departments (ED) and throughout the hospital. The aim of this study is to look at how private hospitals may be used as part of the greater solution in providing Outflow Surge Capacity (OSC) to the public hospitals, and: are private hospitals able to deliver outflow surge capacity in times of great need.
\end{abstract}

MATERIAL AND METHODS: This study was conducted from October 2018 - May 2019 in a selection of public and private hospitals in the greater Dublin (Ireland) region. Ethics approval was obtained and purposive sampling was employed. Semi-structured interviews following a Straussian Grounded Theory (SGT) design were conducted following the recruitment of 16 high-level key stakeholders in 4 hospitals of interest representing both public and private sectors. No demographic data was collected, ensuring anonymity. Data was analysed manually using grounded theory principles, which involved open, axial and selective coding.

RESULTS: All participants were found to be open to utilising private hospitals as OSC. Private hospitals were recognised by public hospitals as having the ability, skills and expertise to assist public hospitals with OSC. High awareness of the need for additional space in acute hospitals was evident. All participants showed concern for current overcrowding hospital wide nationally.

CONCLUSIONS: Public hospitals identified a number of approaches to utilise private hospitals as OSC. Private hospitals showed readiness and agreement to provide OSC, however, willingness was not assessed due to the number of private hospitals included in the study Further research is required to ascertain Government willingness to participate and establish financial accountability should this finding be introduced.

KEY WORDS: surge capacity; disaster planning; disaster management; public-private partnership; mass casualty incident; disaster preparedness 


\section{INTRODUCTION}

Surge capacity is defined as "the ability of a health service to expand beyond its normal capacity to meet increased demand for clinical care" [1].

Ireland's Health Service is overwhelmed with large numbers of patients waiting in ED for long periods - sometimes days, awaiting admission to a bed on a ward. As a result, it would be difficult to provide surge capacity beds in the event of an $\mathrm{MCl}$, as has been highlighted regularly over the last number of years [2-5]. An MCl is described as an event which overwhelms the health care system locally with high numbers of casualties that exceeds the resources available within a relatively quick timeframe [6]. Although major emergencies and $\mathrm{MCl}$ are rare, particularly in Ireland, they create a very real burden on the health care systems preparedness and response [7]. It is further acknowledged that crowds are becoming larger due to increased attendances at sporting events and festivals and such other activities [8].

The aim of this study is to look at how private hospitals may be used as part of the greater solution in providing OSC to the public hospitals, and to identify if private hospitals are able to deliver OSC in times of great need. OSC is further described as moving patients from one hospital to another in order to create additional beds, rather than surge capacity which generally refers to creating additional bed spaces within a facility. This study focuses specifically on a selection of public and private hospitals in the Dublin region. For the purpose of this study, OSC refers to current inpatients in public hospitals who may be moved to private hospitals in order to free up acute-care beds for use in $\mathrm{MCl}$.

Currently, in Ireland, there is a robust National Risk Assessment (NRA) [9] completed by the Department of Defence (2017), in which Ireland's main hazards and vulnerabilities are documented. Although this plan is completed by the Department of Defence, it is in conjunction with Ireland's police force (An Garda Siochana), local authorities and the Health Service Executive (HSE). The HSE is responsible for the governing of all public hospitals in the Republic of Ireland. The NRA document outlines the necessity for each hospital to have its own major emergency plan, but private hospitals are not included in this document, nor have they a structured part to play in case of an $\mathrm{MCl}$.

Private hospitals account for over $20 \%$ of all hospital beds nationally [10]. Ireland is coming under increasing pressure in relation to the number of patients in emergency departments on a daily basis awaiting admission to inpatient wards, sometimes for days $[2,3,11]$. In the event of an $\mathrm{MCl}$, it is suggested it would be difficult to accommodate a surge of patients, due to the number of patients waiting to be decanted for prolonged periods in ED and acute hospital beds [11].

Although the NRA has considered many hazards and vulnerabilities, they have not identified the risk of not having the ability to provide surge capacity beds. Furthermore, data from the Irish Nurses and Midwifery Organisation (INMO) [12] shows Ireland's public hospitals do not currently have the ability to carry out this plan due to high bed occupancy. The INMO has been compiling data on a daily basis from every hospital in Ireland in relation to the number of patients waiting on stretchers in the ED for admission (Fig. 1 and Tab. 1). This data has been collected since 2006. At all times, there are a significant number of patients waiting for beds for a prolonged period of time, and at certain periods of the year this becomes even higher due to seasonal illnesses such as influen$z a$. This data shows that in the event of an $\mathrm{MCl}$, most hospitals in Ireland would be unable to create surge capacity beds to deal with multiple patients.

According to the Health Service Capacity Review [13], bed occupancy is running at between 95-100\% at all times. International average bed occupancy is $85 \%$ [14]. These figures alone highlight the difficulties Irish hospitals would face in the event of an $\mathrm{MCl}$.

This paper aims to identify how willing and able are private hospitals to assist public hospitals in the greater Dublin region with OSC in the event of an $\mathrm{MCl}$. It will look to understand facilitating factors and barriers, as well as to facilitate discussions with key stakeholders. The ultimate aim is to create a method of collaboration between the hospitals of interest resulting in a public-private partnership (PPP) specifically for $\mathrm{MCl}$ response. The long-term goal may facilitate a national collaborative public-private partnership specific to $\mathrm{MCl}$ in Ireland.

To date, there is some research ongoing and available on Ireland's disaster planning and readiness, but no such research has been found involving private hospitals $[7,9,11]$.

\section{MATERIAL AND METHODS}

This study was approved by the Beacon Hospital Research Ethics Committee (REC) and local approval at 


\section{INMO TROLLEY WATCH FIGURES BELOW FOR MAY 31ST 2019}

Every morning at 8 am, INMO members count how many patients are waiting in the Emergency Department for a bed and how many are waiting in wards elsewhere in the hospital. The INMO Trolley Watch counts the number of patients who have been admitted to acute hospitals, but who are waiting for a free bed. These patients are often being treated on trolleys in condors, but they may also be on chairs, in waiting rooms, or simply wherever there's space. The INMO started Trolley Watch in 2004.

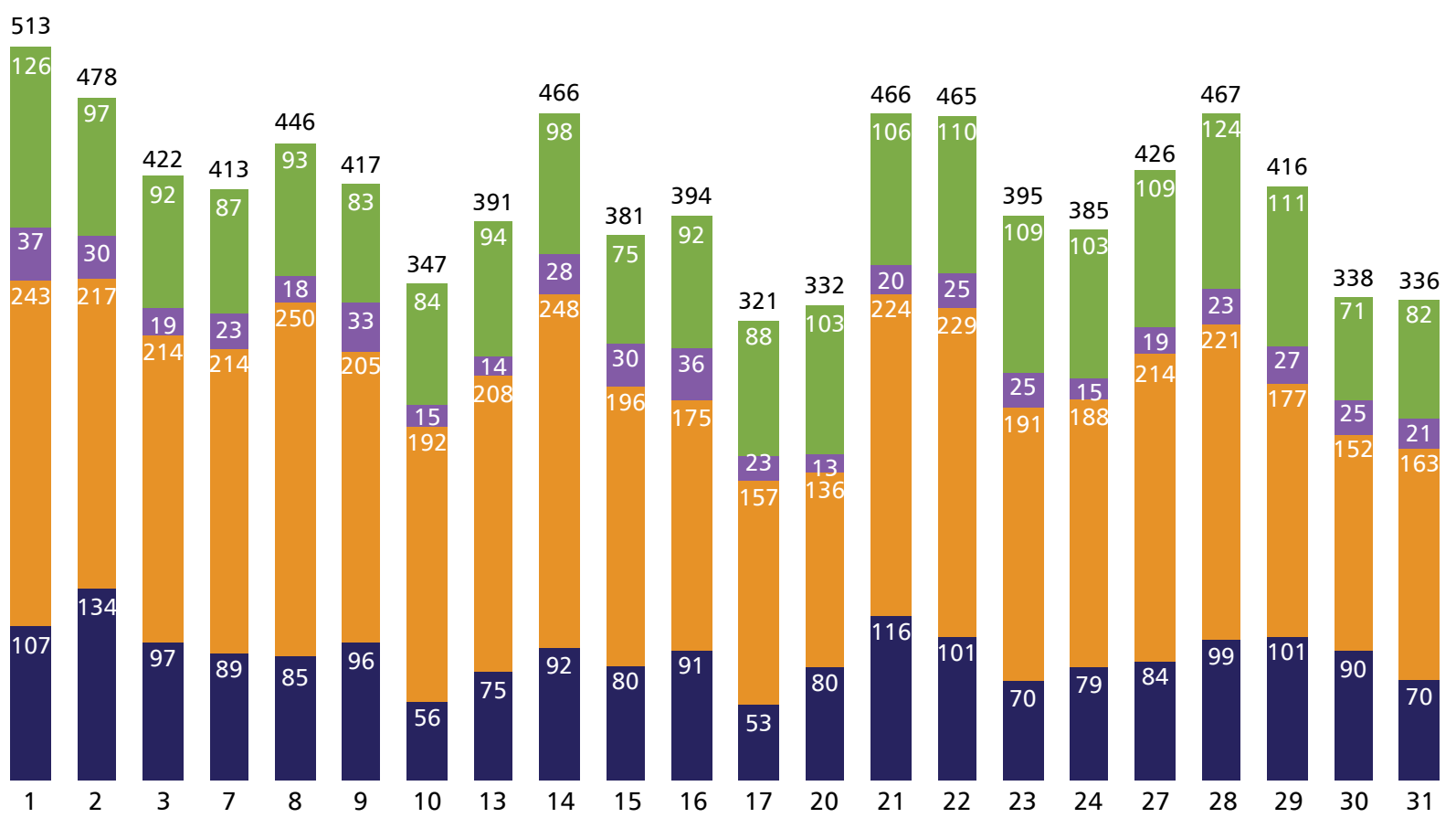

Patients in Dublin waiting in ED for bed on a ward

Patients elsewhere in Ireland waiting in ED for a bed on a ward

Patients in Dublin on additional trolleys added to a ward

Patients elsewhere in Ireland on additional trolleys added to a ward

(INMO, 2019)

FIGURE 1. INMO Trolley Figures for May 2019

each site was also obtained. Purposive sampling was utilised to enable exploration of particular aspects of behaviours relevant to the research questions [15]. This enabled the recruitment of 16 high-level key stakeholders in 4 hospitals of interest representing both public and private sectors. Semi-structured interviews following a Straussian Grounded Theory (SGT) design were conducted between October 2018 and May 2019. No demographics were collected as an additional method of ensuring anonymity. SGT guided the collection and coding of the interview data so that emerging categories were identified and then a substantive theory generated [16]. Data was analysed manually using grounded theory principles, which involved open, axial and selective coding. Open coding was first used to generate concepts. Following this, assistance was sought to ensure the reliability of the codes. Further areas of exploration were discussed. Constant comparisons were made between the transcripts, formulated codes and memos. The SGT method was chosen because of Strauss's willingness to accept the use of a literature review [17].

Inclusion Criteria was staff at senior management level and above, with a working knowledge of disaster planning and management and the ability to influence policy change. This list was utilised as an entry point to generate other individuals who would meet the inclusion criteria. Senior management personnel were then directly approached in person in order to gain access and permission to each site. A Participant Information Leaflet (PIL) and consent forms were sent to potential participants. Those participants who responded and returned the consent forms were then scheduled for face to face interviews. Purposive sampling allowed the use of initial participants to further initiate contact with other relevant potential participants [18]. Participant recruitment continued until the researcher was confident data saturation had been reached. 


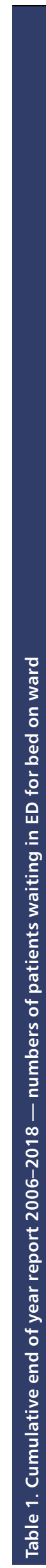

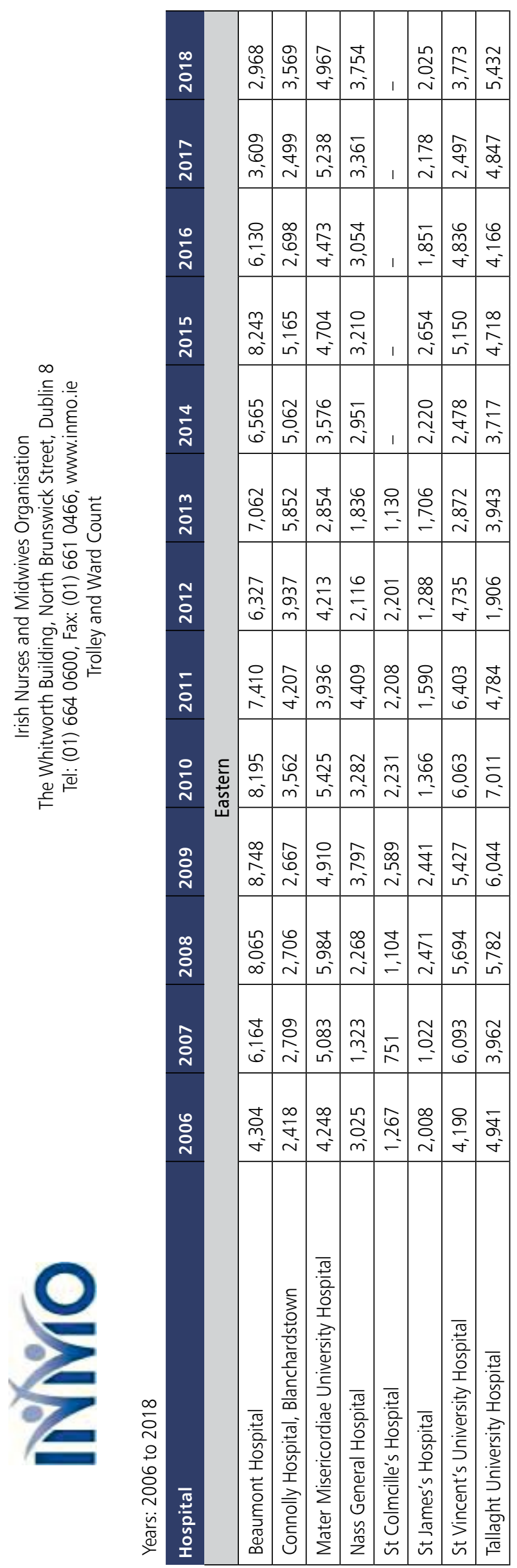

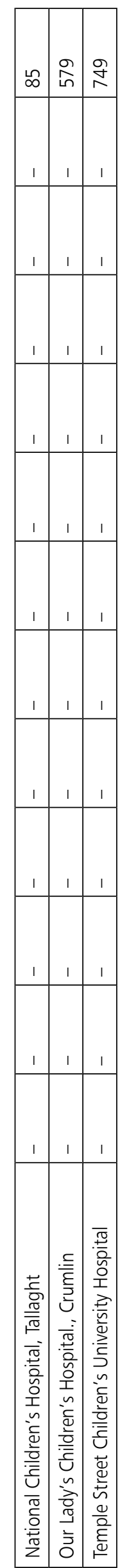

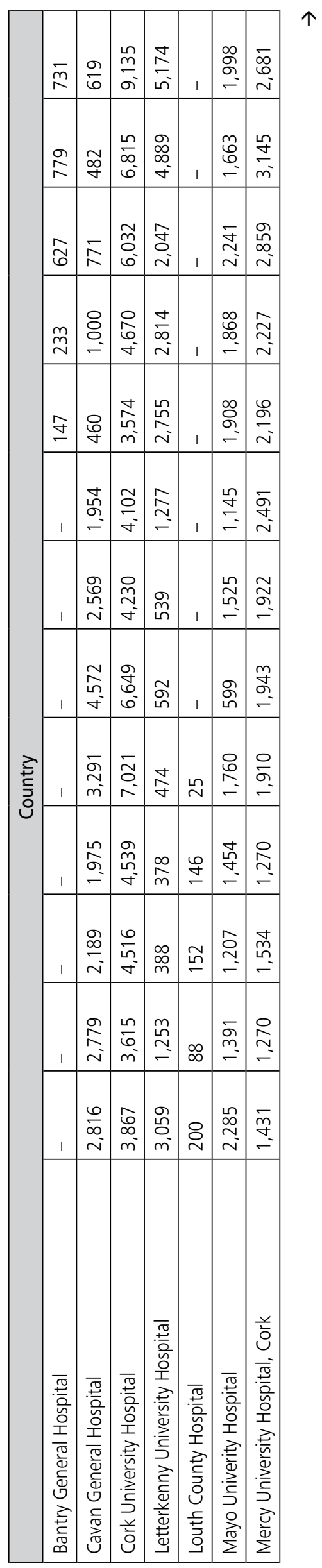




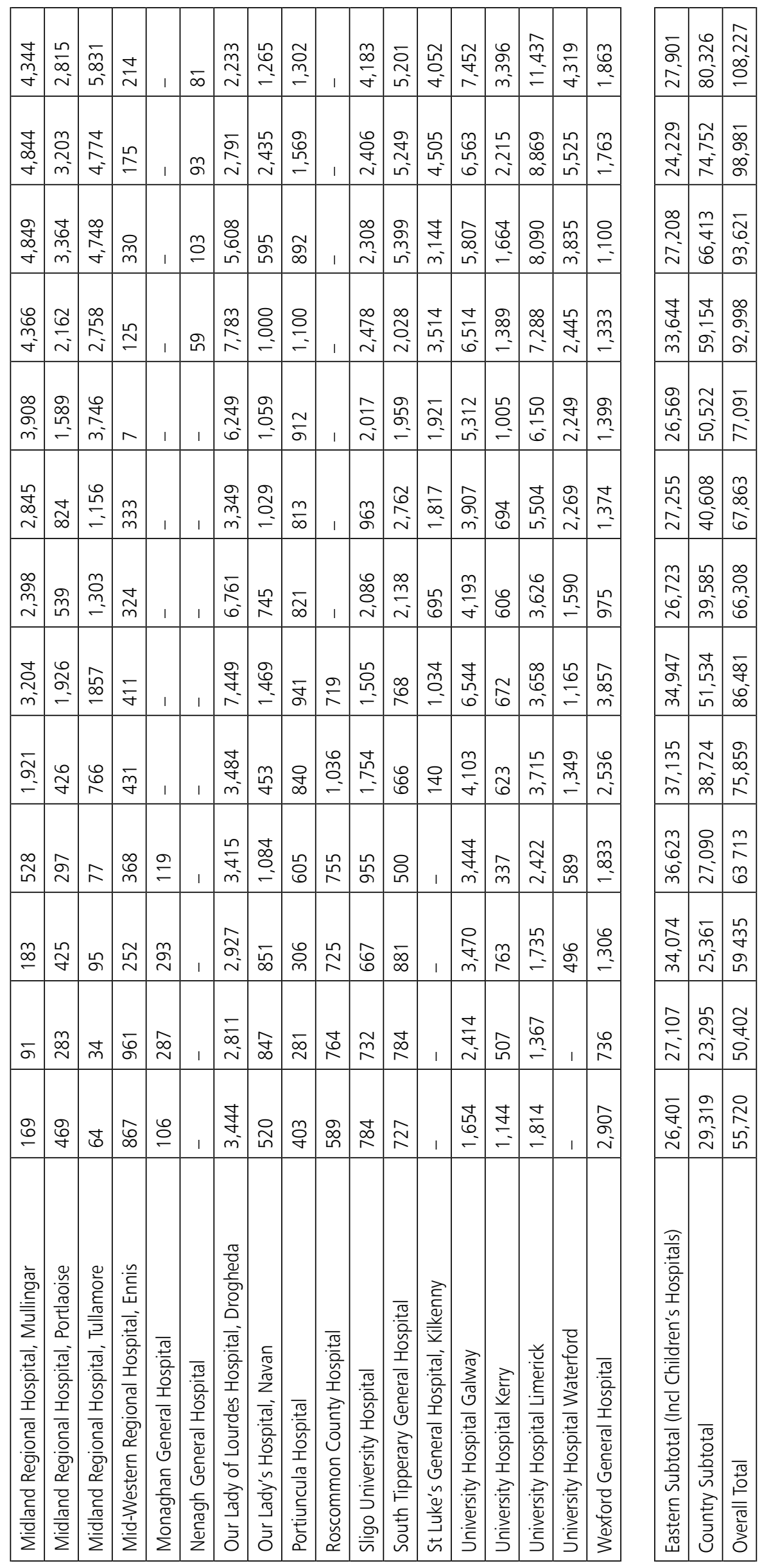


Interviews were conducted in all cases at the participant's place of work. All participants were assured of confidentiality and informed the interviews would be coded anonymously the following transcription. Interviews ranged from 10-40 minutes, depending on the level of participation from the participant. All confidential data and identifiers were removed during transcription. The interviews were recorded with permission and then transcribed verbatim in a secure location.

\section{RESULTS}

A total of 16 interviews were conducted; 8 from the private sector and 8 from the public sector. These particular participants were invited for interview due to their senior positions and ability to affect policy change; as well as their working knowledge of disaster planning and management. A considerable amount of commonality appeared between both groups of participants. In order to ensure and maintain anonymity, transcripts are numbered Participant 1-16 (P 1-16) only, and no differentiation is made between public and private participants. On completion of coding, 2 main themes emerged-Patient advocacy and transport logistics.

\section{Patient advocacy}

One of the major commonalities among both groups was the need and desire of many of the participants to do the greatest good for the greatest number of patients, thereby being efficient patient advocates.

Participants from both the private and public sectors recognised the value of efficient triage of current inpatients and assessing those most suitable to move to alternative facilities in order to free up acute beds. One participant mentioned due to the rareness of an $\mathrm{MCl}$, oftentimes rash decisions are made and patients may be discharged home too soon: "Knowing patients are going to another hospital and not discharged home too early makes the decisions easier, because you know your patients are safe elsewhere without worrying they were sent home too early..." P11.

While one participant was not concerned where the patient went, once they received appropriate treatment: "The main priority is the patient gets to an appropriate referral centre in the fastest time possible to get treatment, it is not really about where the patient will go" P14.
It was evident some participants had not imagined the concept of OSC previously and were confident it would be a positive process: "More patients can be cared for in a general sense if we can move some of our already admitted patients to an alternative hospital" P7.

Utilising private hospitals also seemed to be a relatively new concept but was received positively:

"Using the private hospitals would be a great way of assisting quicker medical management, thereby saving a greater number of lives" P9.

"Using the private hospitals is ideal for really ill patients in the early post-operative phase or in need of specialist treatment like dialysis or chemotherapy" P6.

While many interviewees in public hospitals were not aware of the extent of the services available in the private hospitals, their counterparts were keen to showcase what was available and the benefits they could provide to colleagues in the public sector. In particular, the public hospitals acknowledgement of need for ICU beds is in line with much Irish news, where it is recognised ICU beds are in significant short supply [19]: "We have every facility here to be able to treat all kinds of complex patients and we are really well-positioned considering we already take patients from other ICU departments when they don't have the correct or adequate facilities" P5.

Furthermore, ICU was highlighted a number of times as an area of great need during an $\mathrm{MCl}$ : "... one of the main areas we would really struggle for space in would be ICU. If we could move 1 or 2 ICU patients to another ICU that would definitely be a bonus... major surgery would definitely be delayed if there was no ICU bed postoperatively" P2.

\section{Transport coordination}

Interestingly, although transport or logistics was not a direct question on the interview, every single participant mentioned their concerns regarding how a patient would be moved from one facility to another or how logistically this concept had not been previously considered: "... especially in Dublin where both private and public hospitals are so adjacent to each other, private hospitals should not be negated from being apart from a programme, because there is definitely a private hospital in geographical proximity to every public hospital..." P5.

Concern for families regarding distance from the primary hospital was negated due to the catastrophic nature of $\mathrm{MCl}$ : "I don't think patients would have 
a say in where they would be transferred to or not, because lives are depending on the transfers" P12.

Both of these assumptions match with Joint Commission International $(\mathrm{JCl})$ standards and recommendations in Access to Care and Continuity of care (ACC), whereby ACC1.1 specifies "Patients with emergent, urgent, or immediate needs are given priority for assessment and treatment" [20].

However, one participant was concerned about the extra costs incurred to families: "Do patients want to move? Because of transport issues and family circumstances, the extra costs of buses and taxis might be more than expected" P11.

Many informative statements were made by participants regarding logistics of transferring patients to other facilities, with most acknowledging the HSE and Dublin Fire Brigade (DFB) ambulances would most likely be busy with the initial disaster: "I would be straight on the phone to book a private ambulance to be with us for the rest of the day, that way we would be in control of the calls they do and could direct them where we would need" P2.

Another major factor highlighted staffs concern for their families: "if you are expecting your staff to come in and help in a disaster situation, you have to remember they might not come as they are worried about own families' safety and childcare and such and they are thinking what are you going to do for them?" P5. This concern is also emphasised within $\mathrm{JCl}$ standards, where it is suggested the provision of a safe area for staffs' families would assist with ensuring adequate staffing [21].

Logistically, another participant mentioned many consultants work in both public and private facilities and questioned where would this consultant be in the case of disaster? "It would be important to know what consultants work where..., most of them are in the public and the private. If there was an $\mathrm{MCl}$ they would likely have to leave the private hospital and report to the public, so who is responsible for these patients?" P12.

\section{DISCUSSION}

No previous research is available pertaining to the use of private hospitals during $\mathrm{MCl}$ in Ireland. Specifically, in Ireland, there is very little research into hospitals readiness for $\mathrm{MCl}[7,22]$. Much data is available from national newspapers $[2-5,12,14,19]$ as well as minimal research papers [7, 22] suggesting Irelands already over-packed ED's are not capa- ble of managing a sudden influx of patients in an $\mathrm{MCl}$. From a practical perspective, the researchers' observations have highlighted the importance of including private hospitals into the current national preparedness plan.

It is suggested that private hospitals in the greater Dublin region should be added to the NRA in order to reduce pressure on the already over-packed public system, as a means of decanting already admitted patients from the public hospitals, as OSC. Although there is very little research available internationally on PPP, this particular method has been utilised successfully in Central Brooklyn (United States of America), as a means of ensuring OSC beds [23]. In Ireland, it is not possible to utilise the private hospitals Emergency Departments for this purpose as none of the private hospital ED's open 24 hours per day.

Although no research or plan is without its faults, this paper has identified the merits of including private hospital management in further discussions relating to $\mathrm{MCl}$. Evident from this research is the level of fear among participants that they would be unable to cope on a broader perspective. Also highlighted is the need to look more in-depth at the methods of transportation available to hospitals and the requirement to create a partnership between public and private transport services.

Of greatest significance is the fact that all staff, both public and private; were amenable to utilising/providing assistance to/from their private counterparts. What this paper does not identify, is how to create this alliance or PPP for the purpose of $\mathrm{MCl}$, but it does highlight the need for governmental agencies such as the HSE to include the PHA in further plans.

\section{CONCLUSIONS}

Private Hospitals in the greater Dublin region have the ability to assist public hospitals with OSC during mass casualty incidents. Willingness was not readily assessed due to the lower number of actual private hospitals as participants.

No differentiation was made between public or private hospitals, but questions regarding financial responsibility, governance and availability of transportation methods were raised.

Further research is recommended to include national Government agencies in order to answer these questions. 


\section{Limitations}

It was hoped more private hospitals would participate in this study to give a more representative view, however, access was not granted to two other facilities requested. This led to the willingness of private hospitals not being assessed.

Additionally, this study recognises the participants are representative of the greater Dublin (Ireland) region, but not representative of the country as a whole. It is suggested to carry out a further study including other areas of Ireland in order to get a more representative view, thereby having more valuable input to present to governmental agencies.

\section{Acknowledgements}

This publication is the result of a thesis submitted in partial fulfillment of the requirements for the degree of Master of Science in Disaster Medicine. The author would like to thank all participants for their enthusiasm and involvement in the interviews, without whom the study would not have been possible.

\section{Statement of Competing Interests}

The author reports no competing interests.

\section{REFERENCES}

1. Hospital preparedness checklist for pandemic influenza. Focus on pandemic (H1N1) 2009. http://www.euro.who.int/_data/assets/ pdf_file/0004/78988/E93006.pdf (3.06.2019).

2. Ryan T. 'Inconceivable' that health system would be able to deal with mass casualty event. https://www.thejournal.ie/health-service-warning-mass-casualty-event-3786029-Jan2018/ (3.06.2019).

3. Wall M. HSE has 'no capacity' to deal with nuclear or biological incident. The Irish Times. 2018. https://www.irishtimes.com/news/ ireland/irish-news/hse-has-no-capacity-to-deal-with-nuclear-or-biological-incident-1.3363111 (3.06.2019).

4. O'Regan E. Hospitals 'at full capacity' and could not cope with a major disaster, HSE told. Independent.ie. 2017. https://www.independent.ie/ irish-news/health/hospitals-at-full-capacity-and-could-not-cope-witha-major-disaster-hse-told-36389442.html (14.03.2019).

5. Gantly D. It's the bed numbers, stupid. Irish Medical Times 2017. https://www.imt.ie/news/bed-numbers-stupid-06-10-2017 (03.06.2018).

6. Ben-Ishay 0 , Mitaritonno $M$, Catena $F$, et al. Mass casualty incidents — time to engage. World J Emerg Surg. 2016; 11: 8, doi: 10.1186/ s13017-016-0064-7, indexed in Pubmed: 26848306.

7. Veenema TG, Boland F, Patton D, et al. Analysis of Emergency Health Care Workforce and Service Readiness for a Mass Casualty Event in the Republic of Ireland. Disaster Med Public Health Prep. 2019; 13(2): 243-255, doi: 10.1017/dmp.2018.45, indexed in Pubmed: 29781406.
8. Welzel TB, Koenig KL, Bey T, et al. Effect of hospital staff surge capacity on preparedness for a conventional mass casualty event. West J Emerg Med. 2010; 11(2): 189-196, indexed in Pubmed: 20823971.

9. National Risk Assessment for Ireland 2017 | Emergency Planning. https://www.emergencyplanning.ie/en/news/national-risk-assessment-ireland-2017 (3.06.2019).

10. Private Hospitals Association. 2017. http://privatehospitals.ie/private-hospitals-in-ireland/ (3.06.2019).

11. Fitzgerald C. Private hospital beds to be used to ease emergency department overcrowding. https://www.thejournal.ie/trolley-crisis3787352-Jan2018/ (3.09.2019).

12. ED Trolley Watch/Ward Watch Figures below for 31st August 2016. https://www.inmo.ie/Trolley_Ward_Watch (3.06.2019).

13. Health Service Capacity Review 2018 Executive Report; Review of Health and Capacity Requirements in Ireland to 2031-Findings and Recommendations. https://health.gov.ie/wp-content/uploads/2018/02/71580-DoH-Dublin-Report-v6.pdf (3.06.2019).

14. Ring E. Number of patients on hospital trolleys hits 668. https://www. irishexaminer.com/ireland/number-of-patients-on-hospital-trolleyshits-668-466194.html (3.06.2019).

15. Purposive Sampling. The SAGE Encyclopedia of Qualitative Research Methods. 2008, doi: 10.4135/9781412963909.n349.

16. Kenny M, Fourie R. Contrasting Classic, Straussian, and Constructivist Grounded Theory: Methodological and Philosophical Conflicts. http:// nsuworks.nova.edu/tar/vol20/iss8/9 (24.05.2019).

17. Lawrence J, Tar U. The use of Grounded Theory Technique as a Practical Tool for Qualitative Data Collection and Analysis. The Electronic Journal of Business Research Methods. 2013; 11(1): 29-40.

18. Thai M, Chong L, Agrawal N. Straussian Grounded-Theory Method: An Illustration. NSUWorks. 2012. https://nsuworks.nova.edu/tqr/vol17/ iss26/2/ (22.05.2019).

19. Condon D. Chronic capacity problems in acute hospitals. www. irishhealth.com/article.html?id=25953-Chronic capacity problems in acute hospitals (14.06.2019).

20. Joint Commission InternationalAccreditation Standards for Hospitals. https://www.jointcommissioninternational.org/assets/3/7/JCl_Standards_Only_6th_Ed_Hospital.pdf (25.05.2019).

21. Karim Z. JCl 'Facility Management and Safety (FMS)' standards are crafting safest hospital buildings' equipment and systems, with disaster readiness(!). https://www.linkedin.com/pulse/ jci-facility-management-safety-fms-standards-crafting-zakirul/ (21.06.2019).

22. Reidy $M$, Ryan $F$, Hogan $D$, et al. Preparedness of Hospitals in the Republic of Ireland for an Influenza Pandemic, an Infection Control Perspective. BMC Public Health. 2015; 15: 847, doi: 10.1186/s12889015-2025-6, indexed in Pubmed: 26335570.

23. Dayton C, Ibrahim J, Augenbraun M, et al. Integrated plan to augment surge capacity. Prehosp Disaster Med. 2008; 23(2): 113-119, indexed in Pubmed: 18557290. 